\title{
A Randomized Clinical Trial of an Identity Intervention Programme for Women with Eating Disorders ${ }^{1}$
}

\author{
Karen Farchaus Stein ${ }^{1 *}$, Colleen Corte ${ }^{2}$, Ding-Geng (Din) Chen ${ }^{3}$, Ushapoorna Nuliyalu ${ }^{1}$ \& Jeffrey Wing ${ }^{1}$ \\ ${ }^{1}$ University of Michigan, Ann Arbor, MI, USA \\ ${ }^{2}$ University of Illinois at Chicago, Chicago, IL, USA \\ ${ }^{3}$ University of Rochester, Rochester, NY, USA
}

\begin{abstract}
Objective: Findings of a randomized trial of an identity intervention programme (IIP) designed to build new positive self-schemas that are separate from other conceptions of the self in memory as the means to promote improved health in women diagnosed with eating disorders are reported.

Method: After baseline data collection, women with anorexia nervosa or bulimia nervosa were randomly assigned to IIP $(n=34)$ or supportive psychotherapy (SPI) $(n=35)$ and followed at 1,6 , and 12 months post-intervention.

Results: The IIP and supportive psychotherapy were equally effective in reducing eating disorder symptoms at 1 month post-intervention, and changes were stable through the 12-month follow-up period. The IIP tended to be more effective in fostering development of positive self-schemas, and the increase was stable over time. Regardless of baseline level, an increase in the number of positive self-schemas between pre-intervention and 1-month post-intervention predicted a decrease in desire for thinness and an increase in psychological well-being and functional health over the same period.

Discussion: A cognitive behavioural intervention that focuses on increasing the number of positive self-schemas may be central to improving emotional health in women with anorexia nervosa and bulimia nervosa. Copyright (c) 2012 John Wiley \& Sons, Ltd and Eating Disorders Association.
\end{abstract}

\section{Keywords}

self-schema theory; treatment; psychotherapy; women's health

\section{*Correspondence}

Karen Farchaus Stein, PhD, University of Rochester, 601 Elmwood Avenue, Rochester, NY 14642, USA. Tel: 585-276-6011; Fax: 585-273-1270.

Email: karenf_stein@urmc.rochester.edu

${ }^{1}$ The reported study was completed at the University of Michigan where the first author was on faculty. She has subsequently joined the faculty at the University of Rochester.

Published online 27 September 2012 in Wiley Online Library (wileyonlinelibrary.com) DOI: 10.1002/erv.2195

Disturbances in the self-concept are broadly recognized as a psychosocial risk factor in the aetiology of the eating disorders (ED) and, as such, have been identified an important focus in the ED psychotherapies (for examples, Fairburn, Cooper, \& Shafran, 2003; Wonderlich et al., 2008). Yet despite the centrality of self-concept disturbances in theoretical models of the disorders, theoretically derived and empirically supported interventions that target changes in the self-concept as the mechanism of ED symptom change and health recovery are lacking. In this paper, we report results of a randomized trial of a new psychotherapy for the ED of anorexia nervosa $(\mathrm{AN})$ and bulimia nervosa $(\mathrm{BN})$, referred to as the identity intervention programme (IIP). IIP is based on an empirically supported model that focuses on impairments in organizational properties of the total collection of self-cognitions, referred to as self-schemas, as a key determinant of the maladaptive attitudes and behaviours that characterize the disorders. The IIP seeks to build new positive self-schemas that are distinct and separate from other conceptions of the self in memory as the means to promote recovery and health. The trial examined whether IIP in combination with nutritional counselling would be more effective than supportive psychotherapy (SPI) and nutritional counselling in reducing the attitudinal and behavioural symptoms that characterize the EDs and improving functional health and psychological well-being.

\section{Self-schema disturbance and the EDs: theoretical background and empirical support}

The proposition that the EDs stem from fundamental disturbances in the process of identity development and the resultant collection of self-conceptions or identities is a basic tenet in a diverse array of ED theories ranging from early psychoanalytic, cultural, and feminist approaches (Bjorck, Clinton, Sohlberg, \& Norring, 2007; Bruch, 1982; Lamoureux \& Bottorff, 2005; Tan, Hope, \& Stewart, 2003; Vitousek \& Ewald, 1993). Although theories differ with respect to the causes of the identity disturbances-ranging from genetically determined temperaments (Strober, 1991); disturbances in parent-child relationship due to stressors, mental disorder or other illness (Wechselblatt, Gurnick, \& Simon, 2000); childhood abuse (Polivy \& Herman, 2002); and gender-based cultural pressures that interfere with self-development (Malson, 1999)_all posit that the relative absence of positive identities contributes to the compensatory focus on body weight as the primary source of self-definition. 
Our work on disturbances in identity development associated with the EDs is based on the schema model. Self-schemas are highly elaborated and chronically accessible representations about the self that function to motivate and regulate behaviour (Banting, Dimmock, \& Lay, 2009; Holloway, Waldrip, \& Ickes, 2009; Kendzierski, 1990). Results have shown that positively valenced self-schemas predict effective and reliable behaviours necessary for successful performance in the domain whereas negative selfschemas are associated with anxiety, behavioural inhibition, low levels of involvement in the domain, and contextually dependent evaluations of the self (Feiring, Cleland, \& Simon, 2010; Lips, 1995; Ledoux, Winterowd, Richardson, \& Clark, 2010).

In addition to the number of valenced self-schemas, the organization of self-schemas in memory also influences emotional and behavioural regulation (Chandra \& Shadel, 2007; Dozois et al., 2009). People vary in the extent to which self-schemas are stored in memory as separate units or linked together to form a tightly interrelated network. Highly interrelated schemas derive their meaning from each other and, therefore, function in an 'all-or-nothing' fashion such that activation of one self-schema leads to activation of the related schemas in the network (Linville, 1987). A highly interrelated collection of self-schemas, despite the possibility of including many identities, reflects a high level of overlap in content. Therefore, a highly interrelated collection of self-schemas provides a more limited collection of functionally distinct schemas to guide information processing and regulate emotions and behaviours. Individuals with high interrelatedness among their self-schemas are more likely to do the following: (i) respond to challenging social feedback with less effective coping strategies; (ii) react to stressors with decreases in mood and self-esteem; and (iii) experience physical illness in response to stress than persons who have many independent self-schemas available in memory (Brown \& McConnell, 2009; Linville, 1987, 1985; McConnell, Strain, Brown, \& Rydell, 2009).

Results of our previous work have shown that a self-concept comprised of a highly interrelated collection of few positive and many negative self-schemas contributes to the onset and persistence of ED symptoms. In the first study, women with AN and $\mathrm{BN}$ had fewer positive and more negative self-schemas available in memory and higher interrelatedness among their self-schemas compared with healthy controls, but no differences were found between the two ED groups. Further, the number of positive self-schemas negatively predicted eating disordered attitudes and behaviours, and these effects were mediated through the fat selfschema. A high level of interrelatedness among the self-schemas had a direct influence on eating disordered behaviours and attitudes (Stein \& Corte, 2007a, 2007b). These results were replicated in other studies including a 12-month longitudinal study of college freshmen women that showed that the number of positive and negative self-schemas predicted fat self-schema scores (all measured at baseline), which in turn predicted increases in disordered eating behaviours 6 and 12 months later (Stein \& Corte, 2008; also Stein, Corte, \& Ronis, 2010).

From the ED theoretical perspective and research findings described earlier, the IIP was developed with a focus on modifying the array of self-schemas that comprise the self-concept as the primary means to promote recovery from the ED. We conducted a randomized clinical trial (RCT) to test the efficacy of the IIP compared with SPI in promoting recovery in women with an ED. In keeping with recent work in which mental health is conceptualized as more than the absence of mental illness (Keyes, 2005; Westerhof \& Keyes, 2010), in this study, the effects of the IIP on psychological well-being and functional health are also examined. SPI (Walsh \& Wilson, 1997) was selected as the control treatment for several reasons: (i) it is a manualized treatment for the ED; (ii) like IIP, it does not include a focus on nutritional knowledge and distorted thinking about body weight and shape; hence, we could standardize nutritional counselling across the two treatment conditions; and (iii) it has been used as a control condition in several ED randomized treatment trials. Standardized nutritional counselling based on the Healthy Eating: A Meal Planning System (Neuropsychiatric Research Institute, 1998) was delivered to both groups (i.e. IIP and SPI).

This first trial of IIP was conducted with women with diagnosed $\mathrm{AN}$ or $\mathrm{BN}$ at threshold or subthreshold levels. The decision to include women with both disorders in this trial was based on recent literature that conceptualizes $\mathrm{AN}$ and $\mathrm{BN}$ as a single disorder (Fairburn et al., 2003; Wade, Bergin, Martin, Gillespie, \& Fairburn, 2006) and findings from our earlier study that support the influence of self-schema disturbances in symptoms of both disorders (Stein \& Corte, 2007a, 2007b).

In this first trial of the IIP, the following research hypothesis was tested: compared with women in the SPI group, women in the IIP group will have a greater decrease in ED symptoms and a greater increase in psychological health and well-being. These effects will be mediated through an increase in the number of positive self-schemas available in memory and a decrease in the overall level of interrelatedness among the self-schemas.

\section{Method}

\section{Design}

We conducted a two group randomized experimental design, with a pre-test and post-tests 1, 6, and 12 months post-intervention. Data collection and interventions occurred during the period of 2002 and 2006. Data from this study have been published in a manuscript that addresses correlates of attrition in an RCT for treatment of the ED (Stein, Wing, Lewis, \& Raghunathan, 2011). There is no overlap with RCT results reported in this manuscript.

\section{Participants and recruitment}

Participants were women between the ages of 18 and 35 years with diagnosed threshold or subthreshold $\mathrm{AN}$ or BN. They were recruited through provider referrals and community-based and Internet advertisements in the period between 2003 and 2005 . The Midwestern urban communities in which recruitment occurred were in close proximity to a large state university and other smaller 4-year and community colleges. Potential participants who contacted our research office were asked to complete a brief phone-screening interview that focused on ED symptoms and current psychotropic medication use and psychotherapy treatment involvement. Women who appeared eligible were invited to complete a two-step eligibility assessment that included the Structured Clinical Interview for Diagnostic and Statistical Manual of Mental Disorders, fourth edition (DSM-IV) (SCID) (First, Spitzer, Gibbon, \& Williams, 1997) and a physical health assessment. 
To be eligible to participate in the study, women had to meet the following criteria: (i) 18 and 35 years of age and not pregnant; (ii) full or subthreshold criteria for $\mathrm{AN}$ or BN; (iii) no prescribed psychotropic medication for at least 2 weeks prior to screening; and (iv) involved in no other form of psychotherapy. Subthreshold AN and $\mathrm{BN}$ were defined according to the DSM-IV eating disorders not otherwise specified criteria and endorsement of two items developed by Strober related to levels of distress and dysfunction associated with weight concerns and eating (Strober, Freeman, Lampert, Diamond, \& Kaye, 2000). Women were excluded from participation if they met any of the following criteria: (i) a level of symptom severity that required inpatient treatment; (ii) suicidality; (iii) any lifetime history of schizophrenia or other DSM-IV axis I psychotic disorders or mental retardation; (iv) concurrent DSM-IV axis I disorder at threshold level; and (iv) currently taking prescribed psychotropic medications. Although eligibility/ineligibility criteria were more stringent than typical ED RCT, both axis I disorders such as depression (Evans, Heron, Lewis, Araya, \& Wolke, 2005; Pyszczynski, Holt, \& Greenberg, 1987), substance abuse/ dependence (Stein \& Corte, 2007a, 2007b; Tarquinio, Fischer, Gauchet, \& Perarnaud, 2001), and psychotropic medications have known influences on the structure and related cognitive processes (Herrera-Guzman et al., 2010; King et al., 2012; Levkovitz, Caftori, Richter-Levin, 2002). Because the intervention was focused on cognition- (e.g., targeting self-schema properties as the mechanism) targeting self-schema properties as the mechanism, failure to control individual differences in these variables would impede our ability to determine the efficacy of the intervention.

Participants went through a two-step assessment phase to determine eligibility to participate. The first phase consisted of the informed consent process followed by measurement of height and weight, completion of the Beck Depression Inventory as an initial suicide screen and the SCID. Three experienced clinicians who were trained in the administration of the SCID completed the diagnostic interviews. All SCID interviews and diagnoses were reviewed with the first author to confirm eligibility to participate. Those who met eligibility criteria on the basis of the SCID returned for the second phase that included a physical assessment, blood laboratory studies, and an electrocardiogram.

\section{Random assignment to treatment group}

Women who met eligibility criteria based on SCID and physical assessment were scheduled for baseline data collection that consisted of a battery of measures and a 21-day ecological momentary assessment (EMA). After completion of all baseline measures, random assignment was made, and the participant was scheduled for the first treatment appointment. A stratified randomization method was employed, with strata defined by level and type of illness: (i) full-threshold AN; (ii) full-threshold BN; (iii) sub-threshold AN; and (iv) sub-threshold BN. Dieticians who delivered nutritional counselling and the research assistants who collected post-intervention data were blind to the treatment status and had no other role on the project.

\section{Sample size}

Sample size determination was based on power analysis using Cohen's (1988) methods for a $t$-test as implemented in PASS software (NCSS, Kaysville, UT, USA) (Hintze, 1996) with refinements for analysis of covariance (Taylor \& Innocenti, 1993) and estimates of standard deviations and pre-post correlations based on the preliminary studies. The sample size was selected to provide at least $80 \%$ power and 5\% type I error rate for detecting effects of the treatment. It was calculated that the sample size of 75 per group provided $86 \%$ power to detect a medium-sized effect (i.e. a difference in means equal to $0.5 \mathrm{SD}$ ) using a $t$-test. This assured that practically important effects would be detected. With estimated attrition at each phase of the trial as $22 \%$, a total of 246 referrals to the study were estimated.

\section{Mediating variables}

\section{Self-schema number, valence, and interrelatedness}

Zajonc's card-sorting task (Zajonc, 1960) was used to measure the number of valenced self-schemas and interrelatedness. Participants were given blank index cards and asked to write down all descriptors that are important to how they think about themselves. Next, participants rated each descriptor according to: (i) degree of self-descriptiveness; (ii) degree of importance to one's self-description, (iii) valence, positive, negative, or neutral. In keeping with previous research on self-schemas by Markus and others (Kendzierski, 1990; Kendzierski \& Whitaker, 1997; Markus, 1977; Markus, Hamill, \& Sentis, 1987), descriptors that were rated highly self-descriptive (8-11 on an 11-point scale) and highly important (8-11) were identified as self-schemas. The number of positive (negative, neutral) self-schemas was computed by totalling the number of self-descriptors that met the criteria for a self-schema and were rated positive (negative, neutral). Then, participants were asked to focus on each selfdescriptor separately and to identify all other descriptors that would change if the targeted descriptor was 'changed, absent or untrue of you'. Responses were used to form a dependency matrix. To compare interrelatedness across self-concepts that include varying numbers of descriptors, the measure of interrelatedness was normalized by dividing the total dependency by the total number of possible dependencies of the structure.

The validity of the Markus self-rating to identify self-schemas has been supported by a large collection of studies demonstrating predicted information processing and behavioural differences between schematic and aschematic participants (Kendzierski, 1990; Kendzierski \& Whitaker, 1997; Markus, 1977; Markus et al., 1987; Markus, Smith, \& Moreland, 1985; Stein \& Corte, 2007, 2007). Stein and Corte (2008) used intraclass correlation coefficients (ICC) to show test-retest reliability across a 12-month interval for the number of self-schemas, ICC $=0.44, p<0.001$; number of positive schemas, ICC $=0.53, p<0.001$; number of negative schemas, ICC $=0.51, p<0.001$; and interrelatedness, $\mathrm{ICC}=0.65, p<0.001$.

\section{Primary outcome measures: eating disorder symptoms}

\section{Ecological momentary assessment (EMA) of eating disordered behaviours}

A computerized menu-driven interview was used to prospectively measure ED behaviours for 21-day intervals pre-intervention and post-intervention. Participants were asked to carry with them at 
all times during their waking hours, a PalmPilot computer and were instructed to record all ED behaviours at the time they occur (event triggered). The first screen of the computerized questionnaire was comprised of a list of ED behaviours including binge eating, vomiting, laxative, diuretic and diet pill use, and exercising to lose weight. The second screen focused on the first behaviour endorsed and consisted of specific questions about the enacted behaviour. Responses were automatically recorded with a date and time stamp that could not be erased by the participant. In addition to the eventtriggered recording, a single time-triggered recording was also used. At the end of each day, participants were asked to respond to questions about restricting and fasting over the last 24 hours. Questions for the EMA interview were based on items from the Eating Disorder Examination (Fairburn \& Cooper, 1993) that were rewritten to focus on the behavioural episode just enacted.

Participants were instructed on definitions of target behaviours, use of the PalmPilot, and procedures for recording ED behaviours in a 1-hour individual orientation session. Participants were also given a manual that provided a step-by-step description of the recording and the project phone number in the event that questions or problems with the PDA arose. Participants met with project staff weekly during the EMA period for data transfer and backup.

Ecological momentary assessment has been shown to be a valid and reliable approach to measurement of ED behaviours in samples of women with AN (Burd et al., 2009) and BN (Hilbert \& Tuschen-Caffier, 2007; Stein \& Corte, 2003). Evidence to support the construct, predictive, and criterion-related validity has been shown (Smyth et al., 2009; Tasca et al., 2009;). Further, evidence showing non-reactivity of eating behaviours supports the reliability of EMA (Stein \& Corte, 2003).

The number of episodes of self-induced vomiting, laxative, and diuretic and diet pill use was summed to create an average weekly number of purging behaviour score. Similarly, the number of days of fasting and restricting was used to compute an average weekly restricting score. The numbers of binge episodes and excessive exercise episodes ( $\geq 1.5$ hours of exercise for the purpose of weight control) were averaged to compute a weekly binge episode score and a weekly exercise score, respectively.

\section{Eating disorder inventory}

This widely used self-report questionnaire was used to measure current eating attitudes and behaviours. It consists of 64 items to generate eight sub-scale scores (Garner, 1991). In our study, we used three: drive for thinness, body dissatisfaction, and bulimia. In our sample, alpha coefficients from baseline data were body dissatisfaction alpha $=0.89$, drive for thinness alpha $=0.84$, and bulimia alpha $=0.88$.

\section{Secondary outcome measures: psychological well-being and functional health}

\section{Psychological well-being scale}

The psychological well-being scale (Ryff, 1989) is comprised of six theoretically derived dimensions of psychological well-being including self-acceptance, positive relations with others, autonomy, environmental mastery, purpose in life, and personal growth to measure eudemonic well-being. Each dimension is measured with a 14-item sub-scale. Psychometric studies provide evidence to support the validity and reliability of the measure (Ryff, 1989; Ryffc \& Keyes, 1995; Schmutte \& Ryff, 1997). The measure has been shown to be sensitive to changes in well-being precipitated by discreet life events (Kling, Ryff, \& Essex, 1997; Ryff \& Singer, 1996). In our sample, alpha coefficients based on baseline data were high: self-acceptance alpha $=0.92$, positive relations with others alpha $=0.93$, autonomy alpha $=0.86$, environmental mastery alpha $=$ 0.87 , purpose in life alpha $=0.91$, and personal growth alpha $=0.82$.

\section{Short-Form (36) Health Survey}

The Short-Form (36) Health Survey (SF-36) (Ware, Snow, Kosinski, \& Gandek, 1993) was used to assess changes in functional health along four dimensions: behavioural functioning, perceived well-being, social and role disability, and perceived general health with eight subscales (physical functioning, bodily pain, role limitation due to physical problems, role limitations due to emotional health problems, social functioning, emotional wellbeing, energy/fatigue, and general health perceptions). It has been used extensively to measure treatment outcomes with medical and psychiatric populations and includes dimensions included in recent conceptualizations of mental health. Validity and reliability of the measure have been well established (McHorney, Ware, \& Raczek, 1993; McHorney et al., 1993; Ware \& Sherbourne, 1992; Ware et al., 1993). In our sample at baseline, alpha coefficients ranged from 0.77 to 0.90 .

\section{Intervention protocol}

For both the IIP and SPI conditions, the 20-week treatment consisted of weekly 1-hour individual psychotherapy sessions and 1-hour weekly group psychotherapy sessions with a female master's-prepared psychiatric nurse with extensive experience in delivering individual psychotherapy for ED. One therapist treated participants in both IIP and SPI conditions (individual and group sessions). The therapist received training in IIP and SPI prior to the start of the study by the first author. The content of the IIP is organized in six units, which are briefly outlined in Table 1. Once in the intervention phase of the study, the therapist attended biweekly supervision sessions with the first author, where case presentations and intervention protocols were discussed. Participants in both conditions also received 45-minute nutritional counselling sessions with master's-prepared dieticians (weekly for the first 8 weeks and bi-weekly thereafter). To establish fidelity to the treatment assignment, we coded transcriptions of a randomly selected set of sessions for the number of condition-specific intervention behaviours used by the therapist. All psychotherapy sessions were audiotaped. For each participant, the 20 potential sessions were grouped into four units of five sessions, and one session from each unit was randomly selected for fidelity assessment. Tapes of the selected sessions were transcribed and coded using the Possibilities Project Psychotherapy Coding Questionnaire (Stein, Sargent, \& Rafaels, 2007) developed for this study.

\section{Statistical method}

Longitudinal analyses were performed to analyse intervention effects for ED symptoms [EMA data and Eating Disorder Inventory (EDI)] and indicators of psychological and functional health using data collected at four time points (baseline, 1, 6, and 
Table 1 Six units of the identification intervention programme

\begin{tabular}{ll} 
Unit & \multicolumn{1}{c}{ Goals } \\
\hline Unit 1: orientation & (1) To create an understanding of the intervention programme \\
& (2) To create conceptions of the self in the future that reflect one's \\
personal interests, values, and talents
\end{tabular}

\author{
Unit 2: selecting a possible To select a hoped-for possible self to work on during treatment \\ self

\begin{abstract}
(e.g. referred to as the target possible self)
\end{abstract}
Unit 3: envisioning

Unit 4: planning and doing

Unit 5: reflecting and evaluating

Unit 6: taking stock and saying goodbye
To elaborate the target possible self

To break down the target possible self into smaller, more intermediate steps or goals and plan behaviours needed to achieve goals

To identify barriers that interfered with implementation of the behavioural plan over the last and develop plans for overcoming barriers.

(1) To frame identity development as a lifelong process

(2) To support termination from therapy
Description

This unit consists of four modules that include establishing mutual expectation of patient and therapist roles in treatment, collecting background history, providing an overview of the rationale and methods of the intervention, and fostering development of futureoriented hoped-for possible selves. Exercises in the last module include activities to encourage imagining about the future and recognizing personal interests and talents.

Six modules are designed to stimulate the development of personalized conceptions of selves one would like to be in the future and to identify one possible self that will serve as the focus for the duration of the programme. Activities include generating list of possible future selves, diary writing about the self one would like to be in 3 years, and creating a visual arrangement of possible selves relative to 'your centre or what is most you' and 'challenges you to grow but does not overwhelm you' .

Four modules are designed to foster cognitive elaboration of the target possible. Activities encourage imagining both the steps needed to achieve the possible self goal and the self at the desired end state. They include brainstorming, writing a story, creating a collage about the self I will be, and 'trying on the possible self for a day'.

Four modules seek to identify the personal strengths available and resources needed to achieve intermediate goals. Specific plans are formulated each week for activities needed to be completed to achieve the goal, and mental rehearsal exercises are used to facilitate completion of the action plan.

Activities include systematic review of strengths and barriers, evaluation of strategies, and planning alternative approaches.

Activities include a review of the treatment units and activities that were most helpful in promoting successful achievement of the target possible self and a review of other desired possible selves identified in the process that could be the focus of future efforts.
12 months post-intervention). Data analysis was completed on an intent-to-treat (or as randomized) basis using all available data from the 69 randomized participants. To account for correlation among observations from the same subject, we used linear mixed-effects models to estimate the regression relationship over time and to test whether the regression relationship differed across the two treatment groups. From this model, appropriate $t$-tests were used to assess the statistical significance of intervention effects.

To examine relationships between changes in positive selfschemas and level of interrelatedness with changes in the ED behaviours, a linear regression model was used with change in behaviour as the dependent variable and change in the number of positive schemas or level of interrelatedness as the independent variable, while testing whether to incorporate and adjust for baseline values. Regression model diagnostics for assumptions of normality and variance homogeneity were investigated, and model significance was tested by $F$-test followed by the $t$-tests to assess the statistical significance of the regression coefficients measuring the associations with changes in behaviour and the change in the number of positive schemas or level of interrelatedness. Several regression models were fit, and we found that the covariates for baseline values were not statistically significant, and therefore, the final regression models were simple linear regression model between the change in behaviour and the change in the number of positive schemas or level of interrelatedness. We also conducted a mediation analysis following Baron and Kenny (1986)'s steps to test the self-schema/ level of interrelatedness as a mediator and found that it was not statistically significant, and therefore, the results were not reported.

All analyses were conducted in SAS (version 9.2, SAS Institute Inc., Cary, NC, USA), using a 5\% level of significance and two-sided tests. Analyses and results were not adjusted for multiple comparisons.

\section{Results}

\section{Recruitment and retention}

Although pilot testing was completed to establish feasibility of the trial, referrals were lower than expected, and the target sample size was not reached. As shown in Figure 1, a total of 149 women completed the SCID and physical health screening. Forty-six women $(30.9 \%)$ were ineligible to participate, and five women 


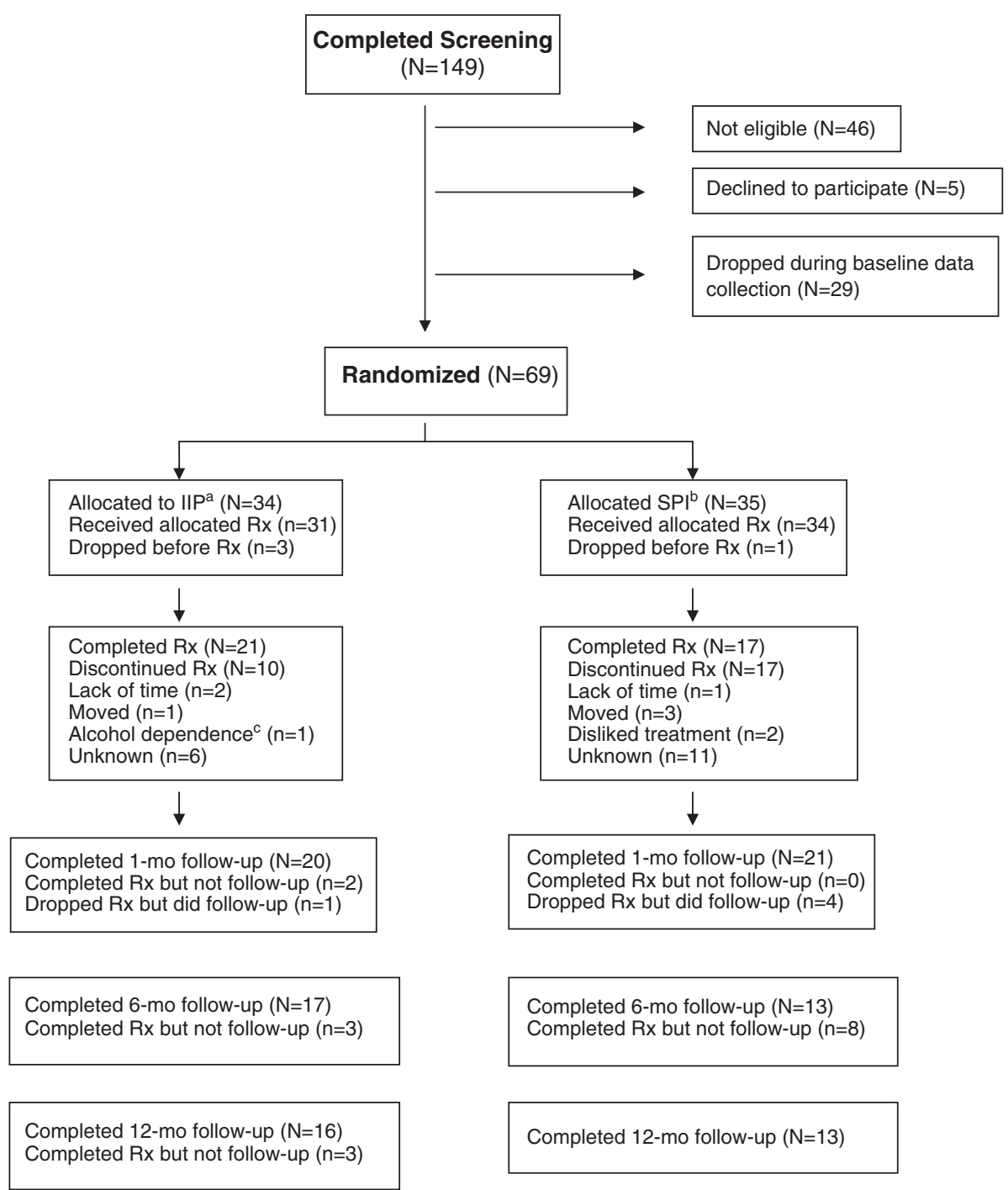

Figure 1 Participant flowchart

(3.4\%) failed to respond to calls after screening was completed and eligibility to participate was established. Twenty-nine women (19.5\%) dropped out of the study during the pre-intervention data collection prior to random assignment. A total of 69 completed baseline data collection and were randomly assigned to a treatment condition (IIP $n=34$ and SPI $n=35)$. A total of 41 women $(59.4 \%)$ completed the 1-month post-intervention data collection (IIP $n=20$ and SPI $n=21)$; 30 women (44\%) completed the 6-month follow-up (IIP $n=17$ and SPI $n=13$ ). At 12-month follow-up, 29 women (42\%) completed data collection (IIP $n=16$ and SPI $n=13$ ). No differences were found between dropout and treatment completers in demographic characteristics, baseline ED symptoms, or self-schema properties (see Stein et al., 2011 for a more detailed description of attrition over time).

\section{Random assignment}

Preliminary data analyses showed that at baseline the two groups did not differ in age [IIP: $M=23.5$ (4.0); SPI: $M=24.4$
(4.1)], years of education [IIP: $M=13.7$ (5.5); SPI: $M=14.1$ ], or race [IIP: $85.3 \%(n=29)$ White; SPI: $67.6 \%(n=23)$ White] (all $p$-values $>0.10$ ). The groups also did not differ according to ED diagnosis; lifetime prevalence of major depressive disorder and lifetime prevalence other than major depressive disorder were similar for the two treatment groups (Table 2).

Also shown in Table 2 are baseline self-schema properties, ED symptom levels, psychological well-being, and functional health scores by group. At baseline, women randomized to the IIP group had significantly higher mean number of fasting/restricting days per week and EDI drive for thinness scores compared with women randomized to the SPI group. The two groups were comparable on all other measures. At baseline, a total of six women had threshold or sub-threshold levels of AN (four women had AN, and two women had sub-threshold AN). One woman had severe symptoms, three had moderate symptoms, and two had mild symptoms. The mean body mass index of women with AN-type disorder was 17.54 (0.44), and five of the six women had amenorrhea. 
Table 2 Diagnoses, self-schema properties, eating disorder symptoms, and psychological and functional health at baseline by treatment group

\begin{tabular}{|c|c|c|c|c|c|}
\hline & \multicolumn{2}{|c|}{ Identity intervention programme $(N=34)$} & \multicolumn{2}{|c|}{ Supportive psychotherapy $(N=35)$} & \multirow[b]{2}{*}{$p$-value } \\
\hline & $N$ & $\%$ & $N$ & $\%$ & \\
\hline Diagnosis & & & & & 0.88 \\
\hline AN & $1 / 34$ & 2.9 & $3 / 35$ & 8.6 & \\
\hline AN sub-threshold & $1 / 34$ & 2.9 & $1 / 35$ & 2.9 & \\
\hline BN & $23 / 34$ & 67.6 & $22 / 35$ & 62.9 & \\
\hline $\mathrm{BN}$ sub-threshold & $9 / 34$ & 26.5 & $9 / 35$ & 25.7 & \\
\hline Lifetime prevalence of major depressive disorder & $9 / 32$ & 28.1 & $15 / 34$ & 44.1 & 0.21 \\
\hline Lifetime prevalence other DSM-IV Axis I disorders & $10 / 34$ & 29.4 & $7 / 35$ & 20.0 & 0.41 \\
\hline \multicolumn{6}{|l|}{ Self-schema properties, M (SD) } \\
\hline No. of positive schemas & \multicolumn{2}{|c|}{$8.47(5.05)$} & \multicolumn{2}{|c|}{$10.1(6.16)$} & 0.23 \\
\hline Interrelatedness & \multicolumn{2}{|c|}{$0.18(0.13)$} & \multicolumn{2}{|c|}{$0.20(0.13)$} & 0.68 \\
\hline \multicolumn{6}{|l|}{ Eating disorder symptoms, $\mathrm{M}(\mathrm{SD})$} \\
\hline Bingeing $^{\dagger}$ & \multicolumn{2}{|c|}{$2.23(2.57)$} & \multicolumn{2}{|c|}{$1.92(1.83)$} & 0.58 \\
\hline Purging & \multicolumn{2}{|c|}{$4.65(4.33)$} & \multicolumn{2}{|c|}{$6.13(5.56)$} & 0.24 \\
\hline Fasting and restricting & \multicolumn{2}{|c|}{$6.00(2.89)$} & \multicolumn{2}{|c|}{$4.11(3.05)$} & $0.01^{*}$ \\
\hline Exercise $^{\dagger}$ & \multicolumn{2}{|c|}{$0.64(1.23)$} & \multicolumn{2}{|c|}{$0.47(0.83)$} & 0.52 \\
\hline EDI, drive for thinness & \multicolumn{2}{|c|}{$15.85(4.45)$} & \multicolumn{2}{|c|}{$12.46(5.72)$} & $0.01^{\star}$ \\
\hline EDI, bulimia & \multicolumn{2}{|c|}{$11.68(6.50)$} & \multicolumn{2}{|c|}{$10.43(5.86)$} & 0.41 \\
\hline EDI, body dissatisfaction & \multicolumn{2}{|c|}{$15.97(8.11)$} & \multicolumn{2}{|c|}{$15.11(6.86)$} & 0.64 \\
\hline \multicolumn{6}{|l|}{ Psychological well-being, M (SD) } \\
\hline Autonomy & \multicolumn{2}{|c|}{$54.88(12.89)$} & \multicolumn{2}{|c|}{$54.69(12.85)$} & 0.95 \\
\hline Environmental mastery & \multicolumn{2}{|c|}{$52.26(12.36)$} & \multicolumn{2}{|c|}{$52.26(11.48)$} & 1.00 \\
\hline Personal growth & & & & & 0.82 \\
\hline Positive relations & & & & & 0.80 \\
\hline Self-acceptance & & & & & 0.94 \\
\hline Purpose in life & & & & & 0.86 \\
\hline Functional health, M (SD) & & & & & \\
\hline Physical functioning & & & & & 0.70 \\
\hline Role limitations due to physical health & & & & & 0.37 \\
\hline Bodily pain & & & & & 0.83 \\
\hline General health & & & & & 0.82 \\
\hline Vitality & & & & & 0.63 \\
\hline Social functioning & & & & & 0.39 \\
\hline Emotional well-being & & & & & 0.11 \\
\hline Mental health & & & & & 0.41 \\
\hline
\end{tabular}

Note: Mean and standard deviations in bracket are reported for continuous variables. Frequency and percentages are reported for categorical variables.

AN, anorexia nervosa; BN, bulimia nervosa; EDI, Eating Disorder Inventory.

${ }^{\dagger}$ Mean number of behaviours including binge eating, purging (vomiting, laxative, diet pill, and diuretic use), and exercise $\geq 1.5$ hours daily for weight control per week.

"Mean number of days (per week) reported restricting or fasting to control weight.

${ }^{*} p$-value less than 0.05 .

The IIP and SPI conditions included 20 individual and 20 group sessions. The number of individual sessions was not significantly different across groups [(individual: IIP $M=15.8$ (6.3); SPI $M=13.1(7.2), t(64)=1.65, p>0.10$. Further, the number of group sessions completed by participants was lower than the individual sessions, but there were no differences between groups [IIP: $M=10.5$ (7.0); SPI: $M=7.5$ (7.2), $t(64)=1.71, p=0.09$.

\section{Treatment fidelity}

A total of 143 tapes were coded. Results showed that for participants randomized to the IIP condition, the therapist used on average $12 \%$ of the total IIP behavioural interventions in a single therapy session compared with less than $0.01 \%$ in a single session for participants in the SPI condition, $t(78.4)=12.63, p<0.0001$. In contrast, the therapist used on average $35 \%$ of the SPI behavioural interventions in a single session for the SPI group compared with only $4 \%$ in the IIP group, $t(118)=-15.23, p<0.0001$. Finally, no significant differences were found between the two groups in the average number of common behavioural interventions used per session, IIP $=23 \%$ and $\mathrm{SPI}=25 \%, t(141) \leq 1$. The difference between the IIP and SPI in the mean number of interventions per session is most likely due to the fact that the IIP interventions were written at a molar level to address a single primary goal per session. In contrast, the SPI interventions referred to specific behavioural strategies used to foster exploration and communication during a therapy session (Stein et al., 2007). 


\section{Treatment outcomes}

The estimated mean scores and standard errors for all four time points (pre-intervention, 1, 6, and 12 month post-intervention) for all outcome variables are shown in Table 3. Table 4 shows the estimated mean change scores within group and between group for baseline to 1-month post-intervention. It can be seen from Table 3 that significant change for all outcome variables occurred only between baseline and 1-month post-intervention. The statistical mixed-effects model analyses further confirmed that after the 1-month post-intervention, all outcomes stabilized (e.g. all changes from 1 to 6 months post-intervention and 1 to 12 months post-intervention were not significant at $p<0.05$ ), and therefore, the 6- and 12-month change scores are not included in Table 4.

\section{Effects of treatment on self-schemas}

From the conceptual model, we predicted that the IIP intervention would lead to a greater increase in positive self-schemas and a greater decrease in interrelatedness among the self-schemas compared with the SPI. As seen in Table 3, the IIP group had an estimated mean increase of 2.86 positive schemas with a $95 \%$ confidence interval ranging from as few as an increase of 0.90 to as many as 4.82 positive self-schemas $(p=0.005)$. Changes in the number of positive self-schemas during the follow-up period ( 1 to 6 and 1 to 12 months were not significant, suggesting that the increase stabilized after 1 month post-intervention. For the SPI group, the change from baseline to 1-month post-intervention was not significant; they had an estimated mean increase of 1.46 (confidence interval $=-0.45,3.38 ; p=0.132$ ). Also, no significant differences in positive self-schemas at post-intervention were found for this group. The between-group difference in mean changes between pre-intervention and post-intervention was not significant $(p=0.315)$ nor were the interaction effects significant during the post-intervention follow-up period.

The expected decrease in self-schema interrelatedness was not found. Both the IIP group and the SPI group experienced no change from baseline to 1-month post-intervention, and consequently, no group difference was found $(p=0.979)$. Estimated means by group at the four time points are shown in Table 3 , and changes in means by group and their difference between pre-intervention and 1 month post-intervention are shown in Table 4 . No group interactions were found during the post-intervention period.

\section{Effects of treatment on eating disorder symptoms}

We also posited that the IIP treatment would lead to greater decreases in ED symptoms compared with the SPI treatment. Results of these analyses are shown in Tables 3 and 4. Both the IIP and SPI groups showed a significant decrease in the weekly mean number of binge eating, purging episodes, and fasting/restricting days (EMA) between baseline and 1-month post-treatment, but between-group differences were not significant (pre-intervention to

Table 3 Estimated mean (SD) scores for all outcome variables at all four time points

\begin{tabular}{|c|c|c|c|c|c|c|c|c|}
\hline \multirow[b]{2}{*}{ Outcome } & \multicolumn{4}{|c|}{ Identity intervention programme group } & \multicolumn{4}{|c|}{ Supportive psychotherapy group } \\
\hline & Pre & Post & Post 6 months & Post 12 months & Pre & Post & Post 6 months & Post 12 months \\
\hline \multicolumn{9}{|l|}{ Self-schemas } \\
\hline No. of positive self-schemas & $8.5(1.2)$ & $11.3(1.4)$ & $12.8(1.7)$ & $11.0(1.8)$ & $10.1(1.2)$ & $11.6(1.3)$ & $9.6(1.9)$ & $10.6(1.9)$ \\
\hline Interrelatedness & $0.2(0.02)$ & $0.2(0.03)$ & $0.2(0.03)$ & $0.3(90.03)$ & $0.2(0.02)$ & $0.2(0.03)$ & $0.2(0.04)$ & $0.2(0.04)$ \\
\hline \multicolumn{9}{|c|}{ Eating disorder attitudes (Eating Disorder Inventory) } \\
\hline Drive for thinness & $15.9(1.0)$ & $4.6(1.2)$ & $4.8(1.4)$ & $6.2(1.5)$ & $12.5(1.0)$ & $6.0(1.2)$ & $5.8(1.6)$ & $7.2(1.6)$ \\
\hline Bulimia & $11.7(0.8)$ & $1.7(1.1)$ & $1.9(1.2)$ & $3.4(1.2)$ & $10.4(0.8)$ & $1.3(1.1)$ & $0.8(1.4)$ & $2.5(1.3)$ \\
\hline Body dissatisfaction & $15.7(1.4)$ & $9.8(1.5)$ & $8.3(1.9)$ & $7.8(2.0)$ & $15.1(1.4)$ & $10.9(1.5)$ & $9.8(2.1)$ & $9.3(2.2)$ \\
\hline \multicolumn{9}{|l|}{ Eating disorder behaviours (EMA) } \\
\hline Binge eating & $2.2(0.4)$ & $0.5(0.4)$ & $0.5(0.4)$ & $0.4(0.5)$ & $1.9(0.3)$ & $0.5(0.4)$ & $0.5(0.5)$ & $1.2(0.5)$ \\
\hline Purging & $4.7(0.8)$ & $1.3(0.9)$ & $1.5(1.0)$ & $1.1(1.2)$ & $6.5(0.8)$ & $1.3(0.9)$ & $1.9(1.1)$ & $2.4(1.2)$ \\
\hline Fasting and restricting & $6.0(0.5)$ & $1.5(0.6)$ & $1.5(0.7)$ & $1.5(0.9)$ & $4.8(0.5)$ & $1.4(0.6)$ & $1.7(0.8)$ & $1.8(0.8)$ \\
\hline Excessive exercise & $0.6(0.3)$ & $0.5(0.3)$ & $0.3(0.4)$ & $0.53(0.4)$ & $0.8(0.3)$ & $0.3(0.3)$ & $0.3(0.4)$ & $0.3(0.4)$ \\
\hline \multicolumn{9}{|l|}{ Psychological well-being (Ryff) } \\
\hline Autonomy & $54.8(2.2)$ & $60.8(2.3)$ & $61.1(2.8)$ & $60.51(3.1)$ & $54.7(2.1)$ & $56.7(2.2)$ & $60.6(3.1)$ & $60.4(3.3)$ \\
\hline Environmental mastery & $52.3(2.1)$ & $62.2(2.3)$ & $59.8(2.9)$ & $57.4(3.1)$ & $52.3(2.1)$ & $58.2(2.3)$ & $59.6(3.3)$ & $61.9(3.4)$ \\
\hline Personal growth & $67.3(1.6)$ & $73.4(1.7)$ & $73.4(2.2)$ & $73.7(2.3)$ & $67.8(1.5)$ & $72.9(1.7)$ & $73.8(2.4)$ & $73.1(2.5)$ \\
\hline Positive relations & $60.1(2.4)$ & $67.73(2.66)$ & $66.69(3.32)$ & $67.57(3.60)$ & $59.23(2.40)$ & $62.50(2.61)$ & $66.12(3.73)$ & $67.74(4.01)$ \\
\hline Self-acceptance & $51.2(2.5)$ & $64.80(2.88)$ & $63.48(3.65)$ & $59.19(3.79)$ & $50.75(2.51)$ & $61.23(2.83)$ & $61.42(4.04)$ & $63.56(4.07)$ \\
\hline Purpose in life & $60.0(2.1)$ & $68.9(2.4)$ & $67.6(2.9)$ & $66.3(3.2)$ & $59.4(2.1)$ & $66.0(2.3)$ & $68.4(3.4)$ & $68.9(3.4)$ \\
\hline \multicolumn{9}{|l|}{ Functional health (SF-36) } \\
\hline Physical functioning & $95.4(1.6)$ & $97.01(2.1)$ & $97.7(2.3)$ & $93.7(2.5)$ & $94.3(1.6)$ & $99.5(2.0)$ & $98.9(2.7)$ & $97.5(2.8)$ \\
\hline Role limitations due to physical health & $85.3(4.2)$ & $88.0(5.6)$ & $94.1(6.0)$ & $78.3(6.4)$ & $90.7(4.2)$ & $97.5(5.4)$ & $92.3(6.8)$ & $91.7(7.1)$ \\
\hline Bodily pain & $76.2(3.6)$ & $79.5(4.8)$ & $82.9(5.1)$ & $86.0(5.4)$ & $78.0(3.6)$ & $78.7(4.6)$ & $76.9(5.8)$ & $76.7(6.1)$ \\
\hline General health & $66.1(3.3)$ & $76.6(3.8)$ & $81.0(4.6)$ & $81.0(4.9)$ & $66.9(3.2)$ & $80.0(3.7)$ & $76.6(5.2)$ & $78.8(5.5)$ \\
\hline Vitality & $48.8(3.3)$ & $63.6(4.3)$ & $57.7(4.6)$ & $61.0(4.9)$ & $45.7(3.2)$ & $62.6(4.1)$ & $50.0(5.3)$ & $60.4(5.5)$ \\
\hline Social functioning & $68.8(3.6)$ & $85.9(4.6)$ & $81.6(5.1)$ & $81.7(5.4)$ & $74.6(3.5)$ & $88.9(4.4)$ & $76.0(5.8)$ & $83.3(6.0)$ \\
\hline Emotional well-being & $52.9(6.5)$ & $74.9(8.7)$ & $62.8(9.2)$ & $77.8(9.8)$ & $68.6(6.4)$ & $74.3(8.2)$ & $61.5(10.5)$ & $77.8(10.4)$ \\
\hline Mental health & $63.1(2.9)$ & $74.6(3.8)$ & $70.8(4.0)$ & $65.5(4.3)$ & $66.1(2.8)$ & $70.8(3.4)$ & $64.6(4.6)$ & $72.3(4.8)$ \\
\hline
\end{tabular}


Table 4 Effects of interventions on self-schema properties, eating disorder symptoms and indicators of psychological and functional health on 1 month post-intervention outcomes by treatment groups

\begin{tabular}{|c|c|c|c|}
\hline & $\begin{array}{l}\text { Identity intervention } \\
\text { programme }\end{array}$ & $\begin{array}{c}\text { Supportive } \\
\text { psychotherapy }\end{array}$ & $\Delta$ \\
\hline & Estimate (SE) & Estimate (SE) & Estimate (SE) \\
\hline \multicolumn{4}{|l|}{ Self-schema properties } \\
\hline \# of Positive Schemas & $2.86(0.99) *$ & $1.46(0.96)$ & $1.39(1.38)$ \\
\hline Interrelatedness & $0.02(0.03)$ & $0.02(0.03)$ & $0.001(0.04)$ \\
\hline \multicolumn{4}{|l|}{ Eating disorder symptoms } \\
\hline Drive for thinness & $-11.2(1.15)^{\star}$ & $-6.53(1.15)^{\star}$ & $-4.69(1.62)^{\star}$ \\
\hline Bulimia & $-9.97(1.14)^{*}$ & $-9.14(1.14)^{\star}$ & $-0.84(1.61)$ \\
\hline Body dissatisfaction & $-5.89(0.88)^{*}$ & $-4.23(0.84)^{*}$ & $-1.66(1.22)$ \\
\hline Bingeing & $-1.72(0.31)^{*}$ & $-1.40(0.31)^{\star}$ & $-0.32(0.43)$ \\
\hline Purging & $-3.37(0.70)^{*}$ & $-5.27(0.69)^{\star}$ & $1.90(0.99)$ \\
\hline Fasting and restricting & $-4.53(0.57)^{\star}$ & $-3.19(0.57)^{\star}$ & $-1.34(0.80)$ \\
\hline Exercise & $-0.10(0.27)$ & $-0.54(0.27)^{\star}$ & $0.44(0.38)$ \\
\hline \multicolumn{4}{|l|}{ Psychological well-being } \\
\hline Autonomy & $5.92(1.3)^{\star}$ & $2.01(1.2)$ & $3.91(1.75)^{\star}$ \\
\hline Environmental mastery & $9.92(1.6)^{\star}$ & $5.98(1.5)^{*}$ & $3.94(2.19)$ \\
\hline Personal growth & $6.15(1.3)^{\star}$ & $5.12(1.2)^{*}$ & $1.03(1.77)$ \\
\hline Positive relations & $7.61(1.7)^{\star}$ & $3.27(1.6)^{*}$ & $4.33(2.35)$ \\
\hline Self-acceptance & $13.6(2.2)^{\star}$ & $10.5(2.2)^{*}$ & $3.09(3.16)$ \\
\hline Purpose in life & $8.95(1.8)^{\star}$ & $6.57(1.8)^{\star}$ & $2.38(2.51)$ \\
\hline \multicolumn{4}{|l|}{ Functional health } \\
\hline Physical functioning & $1.57(2.35)$ & $5.22(2.26)^{\star}$ & $-3.65(3.27)$ \\
\hline $\begin{array}{l}\text { Role limitations due to } \\
\text { physical health }\end{array}$ & $2.73(6.83$ & $6.83(6.57)$ & $-4.09(9.48)$ \\
\hline Bodily pain & $3.34(5.50)$ & $0.69(5.28)$ & $2.66(7.63)$ \\
\hline General health & $10.6(3.01)^{\star}$ & $13.2(2.87)^{\star}$ & $-2.60(4.15)$ \\
\hline Vitality & $14.7(4.65)^{*}$ & $16.9(4.46)^{\star}$ & $-2.20(6.44)$ \\
\hline Social functioning & $17.1(5.00)^{\star}$ & $14.3(4.79)^{\star}$ & $2.84(6.92)$ \\
\hline Emotional well-being & $21.9(10.30)^{\star}$ & $5.73(9.90)$ & $16.2(14.29)$ \\
\hline Mental health & $11.5(4.20)^{*}$ & $4.75(4.03)$ & $6.74(5.82)$ \\
\hline
\end{tabular}

Note: Mixed regression model estimates and standard errors in the bracket are reported.

${ }^{*} p$-value less than 0.05 .

1 month post-intervention period; 1 to 6 months post-intervention and the 1 to 12 months post-intervention follow-up, all $p$-values $>0.05)$. The mean number of weekly excessive exercise episodes significantly decreased between pre-intervention and postintervention for the SPI group, but the interaction effects were not significant.

For women with AN, three of the six completed the 1 month post-intervention follow-up, and their mean body mass index at that point was $20.8(4.47)$. All three remained amenorrheic at 1 and 6 months post-intervention. One of the three reported menstruating at 12 months post-intervention.

For the EDI drive for thinness scale, women in the IIP group reported a significantly greater decrease between pre-intervention and 1 month post-intervention compared with those in the SPI group $(p=0.005)$. For the EDI bulimia and body dissatisfaction scales, both groups experienced significant decreases between baseline and post-intervention, but the group effect was not significant. For both groups, trends in ED attitudes scales stabilized after the 1-month post-intervention follow-up.

\section{Effects of treatment on psychological and functional health}

It was hypothesized that the IIP would contribute to greater improvements in psychological and functional health and wellbeing compared with the SPI treatment. Estimated changes in means by group and their differences can be found in Tables 3 and 4 .

For psychological well-being, we found that the increase between pre-intervention and 1 month post-intervention in the autonomy score (Ryff) was significantly greater for the IIP postintervention compared with the SPI group $(p=0.028)$, and this effect was stable over the 12-month follow-up period. All other well-being scale scores increased between pre-intervention and post-intervention, but the difference between the IIP and the SPI groups was not significant.

For functional health (SF-36), increases were found in the IIP group for all the scores, and these increases were found to be statistically significant with the exceptions of physical functioning, role limitations due to physical health, and bodily pain. Similar increases were seen in the SPI group, but in addition to role limitations due to physical health and bodily pain, emotional well-being and mental health were also not significant. None of the differences between the IIP and SPI groups were found to be significant.

\section{Effects of positive self-schema change on eating disorder symptoms and psychological and functional health}

Because the predicted group differences were generally not found, we focused on increase in positive self-schemas, regardless of treatment condition as a determinant of change in ED symptoms, well-being, and functional health. A key hypothesis motivating this study was that changes in self-schema properties were the mechanism underlying behavioral and psychological change. More specifically, it was hypothesized that increases in the number of positive self-schemas and decreases in the level of interrelatedness among self-schemas were hypothesized to be associated with a decrease in ED behaviours and an increase in psychological and functional health in women with AN and BN. As shown in Table 5, no significant relationships were found between an increase in the number of positive self-schemas and ED behaviours. Only a non-significant trend was found between positive self-schema increase and drive for thinness, suggesting that the greater the increase in number of positive self-schemas, the greater is the decrease in drive for thinness between preintervention and post-intervention.

An increase in the number of positive self-schema between baseline and post-intervention was found to be associated with a significant increase in three psychological well-being scales scores including autonomy, self-acceptance, and purpose in life, and a trend in the same direction was found for the environmental mastery and personal growth scale scores. Only the positive relations with others was not significantly related to baseline to post-intervention increases in positive self-schemas.

For the functional health scores, an increase in the number of positive self-schemas was associated with statistically significant increases in general medical health, vitality, and emotional wellbeing/mental health, and a non-significant trend was found for social functioning. 
Table 5 Effects of changes in positive self-schema properties and level of interrelatedness on eating disorder symptoms and indicators of psychological and functional health

\begin{tabular}{|c|c|c|c|c|c|c|}
\hline & \multicolumn{3}{|c|}{ Associations with positive self-schema } & \multicolumn{3}{|c|}{ Associations with interrelatedness } \\
\hline & Cor & $\beta$ & $p$-value & Cor & $\beta$ & $p$-value \\
\hline \multicolumn{7}{|l|}{ Eating disorder symptoms } \\
\hline Bingeing & -0.13 & -0.05 & 0.46 & -0.03 & -0.45 & 0.86 \\
\hline Purging & -0.11 & -0.08 & 0.52 & -0.09 & -2.62 & 0.60 \\
\hline Fasting and restricting & 0.05 & 0.03 & 0.77 & -0.03 & -0.65 & 0.86 \\
\hline Exercise & -0.22 & -0.05 & 0.19 & -0.04 & -0.30 & 0.84 \\
\hline EDI, drive for thinness & -0.26 & -0.29 & 0.11 & -0.06 & -2.26 & 0.74 \\
\hline EDI, bulimia & -0.08 & -0.08 & 0.63 & -0.20 & -7.14 & 0.23 \\
\hline EDI, body dissatisfaction & -0.02 & -0.02 & 0.89 & 0.29 & 10.07 & 0.08 \\
\hline \multicolumn{7}{|l|}{ Psychological well-being } \\
\hline Autonomy & 0.31 & 0.43 & 0.05 & 0.20 & 10.63 & 0.21 \\
\hline Environmental mastery & 0.28 & 0.46 & 0.07 & 0.05 & 3.06 & 0.76 \\
\hline Personal growth & 0.26 & 0.34 & 0.10 & 0.05 & 2.38 & 0.76 \\
\hline Positive relations with others & 0.14 & 0.24 & 0.39 & 0.04 & 2.86 & 0.79 \\
\hline Self-acceptance & 0.40 & 0.92 & 0.01 & 0.05 & 4.70 & 0.74 \\
\hline Purpose in life & 0.35 & 0.57 & 0.02 & 0.04 & 2.30 & 0.82 \\
\hline \multicolumn{7}{|l|}{ Functional health } \\
\hline Physical functioning & 0.08 & 0.15 & 0.62 & 0.02 & 1.72 & 0.88 \\
\hline Role limitations due to physical health & 0.04 & 0.20 & 0.82 & -0.09 & -17.88 & 0.61 \\
\hline Bodily pain & 0.14 & 0.60 & 0.39 & -0.01 & -0.97 & 0.97 \\
\hline General medical health & 0.33 & 0.96 & 0.04 & -0.16 & -17.50 & 0.34 \\
\hline Vitality (energy/fatigue) & 0.33 & 1.21 & 0.04 & 0.01 & 1.10 & 0.96 \\
\hline Social functioning & 0.30 & 1.23 & 0.07 & -0.17 & -26.95 & 0.31 \\
\hline Role limitations due to emotional problems & 0.39 & 1.38 & 0.01 & 0.12 & 15.71 & 0.48 \\
\hline Emotional well-being/mental health & 0.24 & 2.11 & 0.14 & -0.22 & -72.37 & 0.19 \\
\hline
\end{tabular}

Note: Pearson correlation, parameter estimate from the linear regression model, and the associated p-values are reported. Bolded are $p$-values $<10 \%$.

The results of the interrelatedness models yielded no statistically significant results.

\section{Discussion}

The results of this study suggest that a cognitive behavioural intervention that focuses on increasing the number of positive self-schemas may be central to improving emotional health and well-being in women with the ED of AN and BN. Although both the IIP and SPI approaches were equally effective in reducing ED symptoms, the results provide preliminary evidence to suggest that the IIP was more effective in fostering the development of positive domains of self-definition and that the increase in positive self-schemas found in this group was stable over the 12-month follow-up period. Further, results show that an increase in the number of positive self-schemas, regardless of the treatment type, was predictive of an increase in psychological well-being and emotional aspects of functional health. Contrary to our prediction, however, no significant change in the level of interrelatedness among the self-schemas was detected for either the IIP or SPI groups. Finally, no association was found between the amount of interrelatedness change and the ED symptoms, psychological well-being, or functional health outcomes.

The level of ED behaviours and attitudes at baseline in our sample was somewhat lower than rates reported in other RCTs, but ED attitudes in our sample were comparable with 'severe bulimics' (those who were unsuccessful in outpatient treatment or too sick to participate in outpatient treatment) in another RCT (Zeeck, Weber, Sandholz, Wetzler-Burmeister, Wirsching, \& Hartmann, 2009). At post-intervention, both groups had significant improvements in binge eating and purging behaviours and related ED attitudes of body dissatisfaction and bulimia. However, contrary to our prediction, the changes in ED behaviours and attitudes were generally unrelated to changes in the number of positive selfschemas that occurred during the treatment phase. No ED symptom change was predicted by the positive self-schema change, suggesting that overall, self-schema change is not an explanatory mechanism underlying symptom remediation.

Previous studies have shown that the effect of the number of positive self-schemas on ED behaviours and attitudes is mediated through a stable and elaborated conception of the self as fat (i.e. a fat self-schema) (Stein \& Corte, 2007a, 2007b, 2008). Although it is not possible to determine from this study, a plausible explanation for the observed pattern of findings is that the nutritional counselling component of the intervention programmes modified aspects of the established fat self-schema. In addition to generalized declarative knowledge and incident-specific episodic knowledge, self-schemas also include procedural knowledge related to the behavioural domain in the form of strategies and routines (Kendzierski, 1988). Nutritional interventions including factual knowledge about energy and nutrient needs and strategies for 
healthy eating behavioural patterns may alter procedural knowledge included in the fat self-schema. The change in the fat self-schema knowledge may, in turn, contribute to an overall decrease in ED behaviours and attitudes.

The fact that a broad range of ED behaviours were measured in this study provides an opportunity to determine whether reductions in presenting patterns of ED behaviours are associated with increases in other types of weight control behaviours. Results of many ED clinical trials, particularly those focused on BN, tend to measure a narrow complement of disordered eating behaviours, leaving open the question of whether substitutions rather than elimination of disordered eating behaviours occur. Results of this study show that not only did rates of purging behaviours decrease but days of restricting and fasting also decreased after treatment. Interestingly, exercise was not a commonly used method of weight control, but the SPI intervention did lead to a pre-intervention to post-intervention decrease in this behaviour.

Perhaps most significant, results of this study suggest that an increase in positive self-schemas during the intervention period was predictive of improvements in mental health at postintervention. To date, ED treatment studies have tended to focus on the remediation of behavioral and attitudinal symptoms but generally do not include indicators of improved health. These studies imply that the absence of symptoms is commensurate with recovery to a state of health. Yet there is an emerging consensus within the field of psychiatry that mental health is more than the absence of mental disorder symptoms. A recent approach, referred to as the two-continuum model, is based on the argument that mental illness and health are two distinct but related phenomena that follow different developmental trajectories across adulthood (Westerhof \& Keyes, 2010). In this model, mental health is defined as a state of well-being that includes the following: (i) emotional well-being defined as subjective feelings of life satisfaction and happiness; (ii) psychological well-being defined in terms of individual striving and functional health, the realization of one's potentials; and (iii) social well-being defined as social engagement and societal embeddedness.

Results of this study provide evidence that interventions that contribute to the development of positive self-schemas lead to improvements in the dimension of mental health. At baseline, women in both groups scored below age-specific and genderspecific norms, both on the measure of psychological well-being and the emotional dimensions of functional health. Regardless of the treatment condition, a greater increase in positive selfschemas between the pre-intervention and post-intervention period predicted increases in measures related to psychological well-being and some dimensions of functional health. For psychological well-being, an increase in positive self-schemas predicted increases in the autonomy, environmental mastery, personal growth, self-acceptance, and purpose in life at postintervention. In fact, for women in the IIP group, the postintervention scores on these subscales were sufficiently increased to make them approximately equivalent to the means found in a healthy community-based sample of women at midlife (Ryff, 2002). Only the positive relations with others subscale score change was not associated with changes in the number of positive self-schemas.
An increase in the number of positive self-schemas was also predictive of increases in general health, vitality, and mental health as measured by the SF-36. The general health subscale of the SF-36 taps a comprehensive view of one's health including current health, resistance to illness, and health outlook. The vitality and mental health subscales were designed to measure subjective well-being and therefore are consistent with Westerhof's first dimension of mental health. At baseline, the study groups' means for these three scales were at or lower than the 25th percentile on the basis of national norms for women 25 to 35 years of age. However, at post-intervention follow-up, scores for both groups were improved to at least the 50th percentile, and these increases in scores were predicted by the increase in number of positive self-schemas.

It is important to note that the self-schema theory suggests that positive self-schemas include behavioural routine, strategies, and goals that serve to increase commitment to the domain and motivate effective goal-directed behaviours (Kendzierski, 1988). Additionally, studies have shown that positive self-schemas in a domain are predictive of positive affective states and optimism about the future, which are elements of subjective well-being as defined by Westerhof. Consistent with the self-schema theory, results of this study showed that an increase in positive self-schemas was predictive of an increase in purpose and meaning in life, a sense of autonomy, self-acceptance, and mastery. In addition, an increase in positive self-schemas predicted increases in vitality and mental health, two subscales of the SF-36 that tap subjective well-being as defined by Westerhof.

It is noteworthy that both the treatment and control groups experienced significant increases in social functioning, as measured by the positive relations scale of the well-being measure and the social functioning subscale of the SF-36. But only social functioning was related to the increase in the number of positive self-schemas, and the association did not reach the standard level of significance. Although only speculative, it is possible that the non-specific elements of psychotherapy stemming from the therapeutic relationship contributed to the improvements in the social domain. Given that social well-being is defined as an important component of mental health, continued exploration of the therapeutic active ingredient that contributes to improved social well-being is an important focus for future research.

The decision to use a transdiagnostic approach to the ED in this RCT was based on several factors. First, several theories of the aetiology of AN and BN are similar in their focus on low self-esteem and self-concept disturbances as an important vulnerability contributing to the disorders (Fairburn et al., 2003; Vitousek \& Ewald, 1993). In addition, support for the identity impairment model predicting ED symptoms as a function of self-schema properties has been shown for both populations (Stein \& Corte, 2007a, 2007b). Although women with AN were included in this initial trial, the number of women with AN who were actually enrolled and completed the trial was very small. In addition, the severity of illness and study retention for this subset of the sample were low. Therefore, it is not possible to determine the utility of this approach for this population. Additional research is needed to determine whether increasing the number of positive self-schemas will similarly lead to improvements in subjective and psychological well-being in populations of women with AN. 
Despite the fact that this study showed promising results related to the IIP as a means to promote mental health in women with an ED, several limitations must be noted. The first and most obvious limitation of this study is the small sample size and the high rate of attrition. Although the results of this trial are promising, additional higher-powered studies are required before firm conclusions regarding the efficacy of the intervention can be made. Another important limitation of the study is that women with concurrent DSM-IV axis I diagnoses and those who prescribed psychotropic medications were excluded. The rationale for these exclusion was grounded in evidence that diagnoses such major depressive episode, alcohol abuse/dependence, and anxiety disorders are associated with distinct patterns of self-schema properties that would confound efforts to establish an empirical link between organizational properties of self-schemas and the ED. Similar psychotropic medications alter cognitive processes, which also could serve as a confounder in our study. Although these factors limit generalizability of the findings to broader populations of women with ED, this careful sample definition does allow conclusions to be drawn about the potential benefits of a selfschema-focused intervention. Another limitation of our study that limits generalizability of findings is that our sample had lower levels of disordered eating behaviours at pre-intervention compared with samples in other RCTs. Although eating disordered attitudes were high in this sample, replication with women with more severe levels of disordered eating behaviours is needed. A final limitation of the study is that adherence to the group component of the psychotherapy programmes was relatively low, and therefore, the extent to which this dimension contributed to improvements in well-being remains unknown. The theoretical perspective underlying this aspect of the treatment programme is that social context plays an important role in commitment and development of possible self-goals and contributes to the cognitive elaboration of these new structures. The lower level of adherence to this aspect of the treatment programme leaves the question of its importance in positive self-schema development in this population unknown.

Clearly, additional research is needed to determine the utility of the IIP in the promotion of recovery and health in women with $\mathrm{AN}$ and $\mathrm{BN}$. Yet the results of this initial trial are promising and highlight an approach to ED treatment that goes beyond alleviation of presenting symptoms to the promotion of mental health in wellness in this vulnerable population.

\section{Acknowledgements}

This study is funded by NIH/NINR grant no. R0105277. ClinicalTrials. gov ID NCT01517906.

\section{REFERENCES}

Banting, L., Dimmock, J., \& Lay, B. (2009). The role of implicit and explicit components of exerciser self-schema in the prediction of exercise behavior. Psychology of Sport and Exercise, 10, 80-86.

Baron, R. M., \& Kenny, D. A. (1986). The moderator-mediator variable distinction in social psychological research: Conceptual, strategic and statistical considerations. Journal of Personality and Social Psychology, 51, 1173-1182.

Bjorck, C., Clinton, D., Sohlberg, S., \& Norring, C. (2007). Negative self-image and outcome in eating disorders: Results at 3-year follow-up. Eating Behavior, 8, 398-406.

Brown, C., \& McConnell, A. (2009). Effort or escape: Self-concept structure determines self-regulatory behavior. Self and Identity, $8,365-377$

Bruch, H. (1982). Anorexia nervosa: Therapy and theory. The American Journal of Psychiatry, 139, 1531-1538.

Burd, C., Mitchell, J., Crosby, R., Engel, S., Wonderlich, S., Lystad, C., et al. (2009). An assessment of daily food intake in participants with anorexia nervosa in the natural environment. International Journal of Eating Disorders, 42, 371-374.

Chandra, S., \& Shadel, W. (2007). Crossing disciplinary boundaries: Applying financial portfolio theory to model organization of the self-concept. Journal of Research in Personality, 41, 346-373.

Cohen, J. (1988). Statistical power analysis for the behavioral sciences (2nd edn.). Hillsdale, NJ: Lawrence Erlbaum Associates.

Dozois, D., Bieling, P., Patelis-Siotis, I., Hora, L. Chudzik, S., McCabe, K., et al. (2009). Changes in self-schema structure in cognitive therapy for major depressive disorder: A randomized clinical trial. Journal of Consulting and Clinical Psychology, 77, 1078-1088.

Evans, J., Heron, J., Lewis, G., Araya, R., \& Wolke, D. (2005). Negative self-schemas and the onset of depression in women: longitudinal study. The British Journal of Psychiatry, 186, 302-307.
Fairburn, C.G., \& Cooper, Z. (1993). The eating disorder examination. In C.G. Fairburn, \& T.G. Wilson (Eds.), Binge eating: Nature, assessment \& treatment (12th edn., pp. 317-360). New York: Guilford Press.

Fairburn, C., Cooper, Z., \& Shafran, R. (2003). Cognitive behavior therapy for eating disorders: A "transdiagnostic" theory and treatment. Behavior Research and Therapy, 41, 509-528.

Feiring, C., Cleland, C., \& Simon, V. (2010). Abuse-specific selfschemas and self-functioning: A prospective study of sexually abused youth. Journal of Clinical Child and Adolescent Psychology, 39, 35-50.

First, M.B., Spitzer, R.L., Gibbon, M., \& Williams, J. (1997). User's guide for the Structured Clinical Interview for DSM-IV axis I disorders. Washington, DC: American Psychiatric Press Inc.

Garner, D. (1991). Eating Disorders Inventory-2 professional manual. Odessa, FL: Psychological Assessment Resources.

Herrera-Guzman, I., Herrera-Abarca, J., Gudayol-Ferre, E., HerreraGuzman, D., Gomez-Carbajal, L., Pena-Olvira, M., et al. (2010). Effects of selective serotonin reuptake and dual serotonergicnoradrenergic reuptake treatment on attention and executive functions in patients with major depressive disorders. Psychiatry Research, 177, 323-329.

Hilbert, A., \& Tuschen-Caffier, B. (2007). Maintenance of binge eating through negative mood: A naturalistic comparison of binge eating disorder and bulimia nervosa. International Journal of Eating Disorders, 40, 521-530.

Hintze, J.L. (1996). PASS 6.0 user's guide. Kaysville, UT: Number Cruncher Statistical Systems.

Holloway, R., Waldrip, A., \& Ickes, W. (2009). Evidence that simpatico self-schema accounts for differences in the self-concepts and social behavior of Latinos versus Whites and Blacks. Journal of Personality and Social Psychology, 96, 1012-1028.

Kendzierski, D. (1988). Self-schemata and exercise. Basic and Applied Social Psychology, 9, 45-59.
Kendzierski, D. (1990). Exercise self-schemata: Cognitive and behavioral correlates. Health Psychology, 9, 69-82.

Kendzierski, D., \& Whitaker, D. (1997). The role of self-schema in linking intentions with behavior. Personality \& Social Psychology Bulletin, 23, 139-147.

Keyes, C.L.M. (2005). Mental illness and/or mental health? Investigating axioms of the complete state model of health. Journal of Consulting and Clinical Psychology, 73, 539-548.

King, M., MacDougall, A., Ferris, S., Levine, B., MacQueen, G., \& McKinnon, M. (2012). A review of factors that moderate autobiographic memory performance. Journal of Clinical and Experimental Neuropsychology, 32, 1122-1144.

Kling, K., Ryff, C., \& Essex, M. (1997). Adaptive changes in the selfconcept during a life transition. Personality and Social Psychology Bulletin, 23, 981-990.

Lamoureux M, \& Bottorff, J.. (2005). 'Becoming the real me': Recovering from anorexia nervosa. Health Care for Women International, 26, 170-188.

Ledoux, T., Winterowd, C., Richardson, T., \& Clark, J. (2010). Relationship of negative self-schemas and attachment styles with appearance schemas. Body Image, 7, 213-217.

Levkovitz, Y., Caftori, R., Avital, A. \& Richter-Levin, G. (2002). The SSRIs drug Fluoxetine, but not the noradrenergic tricyclic drug despramine, improves memory performance during acute major depression. Brain Research Bulletin, 58, 345-350.

Linville, P. (1985). Self-complexity and affective extremity: Don't put all of your eggs in one cognitive basket. Social Cognition, 3, 94-120.

Linville, P. (1987). Self-complexity as a cognitive buffer against stress-related illness and depression. Journal of Personality and Social Psychology, 52, 663-676.

Lips, H. (1995). Through the lens of mathematical/scientific selfschemas: Images of students' current and possible selves. Journal of Applied Social Psychology, 25, 1671-1699. 
Malson, H. (1999) Women under erasure: Anorexia bodies in postmodern context. Journal of Community \& Applied Social Psychology, 9, 137-153.

Markus, H. (1977). Self-schemata and processing information about the self. Journal of Personality and Social Psychology, 35, $63-78$.

Markus, H., Hamill, R., \& Sentis, K. (1987). Thinking fat: Selfschemas for body weight and the processing of weight relevant information. Journal of Applied Social Psychology, $17,50-71$.

Markus, H.R., Smith, J., \& Moreland, R. (1985). Role of the selfconcept in the perception of others. Journal of Personality and Social Psychology, 49, 1494-1512.

McConnell, A.R., Strain, L.M., Brown, C.M., \& Rydell, R. (2009). The simple life: On the benefits of low-self-complexity. Personality and Social Psychology Bulletin, 35, 823-835.

McHorney, C.A., Ware Jr., J.E., \& Raczek, A.E. (1993). The MOS 36-item short-form health survey (SF-36): II. Psychometric and clinical tests of validity in measuring physical and mental health constructs. Medical Care, 31(3), 247-263.

Neuropsychiatric Research Institute (1998). Healthy eating meal planning system. Fargo, ND: NRI Press.

Polivy, J., \& Herman, P. (2002). Causes of the eating disorders. Annual Review of Psychology, 53, 187-213.

Pyszczynski, T., Holt, K., \& Greenberg, J. (1987). Depression, selffocused attention, and expectancies for positive and negative future life events for self and other. Journal of Personality and Social Psychology, 52, 994-1001.

Ryff, C.D. (1989). Happiness is everything, or is it? Explorations on the meaning of psychological well-being. Journal of Personality and Social Psychology, 57, 1069-1081.

Ryff, C.D. (2002). Means and standard deviations for the psychological well-being scale from a variety of studies. [unpublished raw data].

Ryff, C.D., \& Keyes, C. (1995). The structure of psychological well-being revisited. Journal of Personality and Social Psychology, 69, 719-727.

Ryff, C.D., \& Singer, B. (1996). Psychological well-being: Meaning, measurement, and implications for psychotherapy research. Psychotherapy and Psychosomatics, 65(1), 14-23.

Schmutte, P. S., \& Ryff, D. C. (1997). Personality and well-being: What is the connection? Journal of Personality and Social Psychology, 73, 549-559.
Smyth, J., Wonderlich, S., Sliwinski, M., Crosby, R., Engel, S., Mitchell, J., et al. (2009). Ecological momentary assessment of affect, stress, and binge-purge behaviors: Day of week and time of day effects in the natural environment. International Journal of Eating Disorders, 42, 429-436.

Stein, K.F., \& Corte, C. (2003). Ecologic momentary assessment of eating disordered behaviors. International Journal of Eating Disorders, 34, 349-360.

Stein, K.F., \& Corte, C. (2007a). Identity impairment and the eating disorders: Content and organization of the self-concept in women with anorexia nervosa and bulimia nervosa. European Eating Disorders Review, 15, 58-69.

Stein, K.F., \& Corte, C. (2007b). Self-cognitions in antisocial alcohol dependence and recovery. Western Journal of Nursing Research, 29, 80-99.

Stein, K.F., \& Corte, C. (2008). The identity impairment model: A longitudinal study of self-schemas as predictors of disordered eating behaviors. Nursing Research, 57, 182-190.

Stein, K.F., Corte, C., \& Ronis, D. (2010). Personal identities and disordered eating behaviors in Mexican American women. Eating Behaviors, 11, 197-2000.

Stein, K.F., Sargent, J., \& Rafaels, N. (2007). Intervention research: Establishing fidelity of the independent variable in nursing clinical trials. Nursing Research, 56, 54-62.

Stein, K.F., Wing, J., Lewis, A., \& Raghunathan, T. (2011). An eating disorder randomized clinical trial and attrition: Profiles and determinants of dropout. International Journal of Eating Disorders, 44, 356-368.

Strober, M. (1991). Disorders of the self in anorexia nervosa: An organismic-developmental paradigm. In C. Johnson (Ed.), Psychodynamic treatment of anorexia nervosa and bulimia (pp. 354-373). New York: Guilford Press.

Strober, M., Freeman, R., Lampert, C., Diamond, J., \& Kaye, W. (2000). A controlled family study of anorexia nervosa and bulimia nervosa: Evidence of shared liability and transmission of partial syndromes. The American Journal of Psychiatry, 157, 393-401.

Tan, J., Hope, T., \& Stewart, A. (2003). Anorexia nervosa and personal identity: The accounts of patients and their parents. International Journal of Law and Psychiatry, 26, 533-548.

Tarquinio, C., Fischer, G., Gauchet, A., \& Perarnaud, J. (2001). The self-schema and addictive behaviors: Studies of alcohol patients. Swiss Journal of Psychology, 60, 73-81.
Tasca, G., Illing, V., Balfour, L., Krysanski, V., Demidenko, N., Nawakowski, J., et al. (2009). Psychometric properties of selfmonitoring of eating disorder urges among treatment-seeking women: Ecological momentary assessment using a daily diary method. Eating Behaviors, 10, 59-61.

Taylor, M., \& Innocenti, M. (1993). Why co-variance: A rationale for using analysis of covariance procedures in randomized studies. Journal of Early Intervention, 17, 455-466.

Vitousek, K.B., \& Ewald, L.S. (1993) Self-representation in the eating disorders: A cognitive perspective. In Z. Segal, \& S. Blatt (Ed.), The self in emotional disorders: cognitive and psychodynamic perspective (pp. 221-257). New York: Guilford Press.

Wade, T., Bergin, J., Martin, N., Gillespie, N., \& Fairburn, C. (2006). A transdiagnostic approach to understanding eating disorders. The Journal of Nervous and Mental Disease, 194, 510-517.

Walsh, B.T., \& Wilson, G.T. (1997). Supportive psychotherapy manual.

Ware Jr., J.E., \& Sherbourne, C.D. (1992). The MOS 36-item short form health survey (SF-36). I. Conceptual framework and item selection. Medical Care, 30(6), 473-483.

Ware Jr., J.E., Snow, K.K., Kosinski, M., \& Gandek, B. (1993). SF-36 Health Survey: Manual and interpretation guide. Boston: New England Medical Center Health Institute.

Wechselblatt, T., Gurnick, G., \& Simon, R. (2000). Autonomy and relatedness in the development of anorexia nervosa: A clinical case series using grounded theory. Bulletin of the Menninger Clinic, 64, 91-123.

Westerhof, G., \& Keyes, C. (2010). Mental illness and mental health: The two continua model across the lifespan. Journal of Adult Development, 17, 110-119.

Wonderlich, S., Engel, S., Peterson, C., Robinson, M., Crosby, R., Mitchell, J., et al. (2008). Examining the conceptual model of integrative cognitive-affective therapy for BN: Two assessment studies. International Journal of Eating Disorders, 41, 748-754.

Zajonc, R.B. (1960). The process of cognitive tuning in communication. Journal of Abnormal and Social Psychology, 61, 159-167.

Zeeck, A., Weber, S., Sandholz, A. Wetzler-Burmeister, E., Wirsching, M. \& Hartmann, A. (2009). Inpatient versus day clinic treatment for bulimia nervosa: A randomized trial. Psychotherapy and Psychosomatics, 78, 152-160. 